Referencia para citar este artículo: Barcia-Lehmann, R. (2019). La custodia indistinta, como concepto privilegiando, frente a la custodia exclusiva como forma de custodia unilateral. Revista Latinoamericana de Ciencias Sociales, Niñez y Juventud, 17(1), 139-151. doi:https://dx.doi.org/10.11600/1692715x.17108

\title{
La custodia indistinta, como concepto privilegiando, frente a la custodia exclusiva como forma de custodia unilateral ${ }^{*}$
}

\author{
RODRIGO BARCIA-LEHMANN ${ }^{* *}$ \\ Profesor Universidad Finis Terrae, Chile.
}

Artículo recibido en mayo 3 de 2018; artículo aceptado en octubre 1 de 2018 (Eds.)

- Resumen (descriptivo): el presente artículo pone de manifiesto la necesidad de articular la custodia unilateral, como indistinta, en lugar de exclusiva. Así, ambas formas de custodia tendrían una aplicación diferente, como formas de asignación unilaterales de derechos de filiación. La custodia indistinta sería la regla general, en cambio la exclusiva sería una forma de asignación más bien excepcional y especifica de protección del niño.

Palabras clave: custodia unilateral, custodia exclusiva, custodia conjunta (tomadas de: https:// espana.leyderecho.org/custodia/).

Palabra clave autor: custodia indistinta.

Indiscriminate custody as a privileged concept in relation to exclusive custody as a form of unilateral custody

- Abstract (descriptive): This article highlights the need to consider the concept of unilateral custody as a type of custody that is indiscriminate rather than exclusive. Thus, both forms of custody would have different application, as unilateral forms of the assignment of rights for parents. Indiscriminate custody would be the general rule, while exclusive custody would be for exceptional cases involving specific forms of child protection.

Key words: unilateral custody, exclusive custody, joint custody (Taken from: https://espana. leyderecho.org/custodia/).

Author's key word: Indiscriminate custody.

\section{A custódia indistinta, como um conceito que privilegia a custódia exclusiva como forma de custódia unilateral}

- Resumo (descritivo): este artigo destaca a necessidade de articular a custódia unilateral, como indistinta em lugar de exclusiva. Assim, ambas formas de custódia teriam uma aplicação diferente, como formas unilaterais de cessão de direitos de filiação. A custódia indistinta seria a regra geral, enquanto a custódia exclusiva seria uma forma bastante excepcional e específica de proteção à criança.

El presente artículo de investigación científica y tecnológica forma parte del Proyecto Fondecyt $\mathrm{N}^{\circ} 1150454$, de investigación: «Facultades y deberes del padre no custodio». La investigación duró exactamente dos años, de marzo del 2015 a febrero del 2016. Área: Ciencias Sociales; subárea: Derecho.

** Abogado; MBA Economía y Dirección Internacional de Empresas, Universidad Autónoma de Madrid; European Master in Law and Economics, Complutense und Hamburg Universität, y Doctor en Derecho, Universidad Complutense de Madrid. Orcid: 0000-0003-1021-446X. Índice H5: 7. Correo electrónico: rbarcia@uft.cl 
Palavras-chave: custódia unilateral, custódia exclusiva, custódia conjunta (Tomado de: https:// espana.leyderecho.org/custodia/).

Palabra-chave autor: custas indistintos.

-1. Introducción. -2. ¿Qué aspectos diferencian el cuidado personal exclusivo o indistinto, como formas de cuidado unilateral, del compartido? -3. ¿Qué sustenta, desde el campo científico, la corresponsabilidad? -4. ¿Cuál es el alcance y contenido de la custodia compartida? -5. Contenido de la custodia unilateral, exclusiva o indistinta con relación a la patria potestad en el Derecho español y nula aplicación de la corresponsabilidad en el Derecho chileno. -6. Las distintas tipologías de custodia que se proponen en caso que los padres no convivan. -7. Resultados y conclusiones: La necesidad que la custodia indistinta sea la regla general y la exclusiva la excepción. -Lista de referencias

\section{Introducción}

El presente trabajo busca establecer un concepto moderno de guarda o custodia — para el Derecho español - o cuidado personal — para el chileno- (en adelante sistemas de custodia), en caso de separación de los padres, que sea una aplicación concreta de los principios del interés superior del niño y corresponsabilidad. Este artículo se centra en estos dos ordenamientos jurídicos, dado que establecen formas de custodia unilateral privilegiada.

Esta investigación tiene el mérito de compatibilizar los sistemas de custodia unilateral con el moderno Derecho de la Infancia, que se sustenta en los trabajos científicos más relevantes, que se han generado respecto de la custodia. El objetivo principal de la presente reflexión es determinar el contenido de la custodia unilateral como sistema legal supletorio privilegiado, separando la custodia unilateral exclusiva e indistinta. Así, se critica las tesis generalmente aceptada, hace un tiempo atrás, por la cual se entendía que el cuidado unilateral era exclusivo para el padre custodio. Esta tesis sostenía que el cuidado unilateral exclusivo comprendía todos los aspectos cotidianos que se centraban en el padre custodio. El que muchos ordenamientos jurídicos, sobre todo en Latinoamérica (como en Uruguay, Paraguay, Ecuador, Chile, etc.), consagren sistemas de custodia unilateral, - y lamentablemente exclusiva - conduce a que se establezcan verdaderos sistemas de deberes y facultades o derechos desnudos para el padre no custodio. Ello atenta contra forma en que, a raíz de la Convención de Derechos del Niño, se entiende el Derecho de la infancia.

\section{2. ¿Qué aspectos diferencian el cuidado personal exclusivo o indistinto, como formas de cuidado unilateral, del compartido?}

El presente trabajo busca diferenciar entre cuidado exclusivo e indistinto, como formas de cuidado unilateral. Y ello se debe a que las formas de custodia unilateral se han visto fuertemente modificadas por el principio de corresponsabilidad. La promoción de una participación activa de ambos padres en la formación de los hijos es promovido por la mayoría de los estudios clínicos, y ha llevado a promoverla incluso a través de planes estatales, como el Personal Responsibility and Work Opportunity Reconciliation Act (Ley de Reconciliación Responsabilidad Personal y Oportunidad de Trabajo la Administración del Presidente Clinton) (Miller, 2006). Ello se debe a múltiples aspectos entre los cuales caben destacar que un sistema de corresponsabilidad - aunque establezca una regla general de custodia unilateral - debe establecer deberes y facultades conjuntos y propios del padre no custodio (Barcia-Lehmann, 2017).

En el Derecho español los deberes y facultades del padre no custodio se desprenden de los deberes de cuidado y velar por los hijos (arts. 154, 103-1'a 110 y 111 Código Civil español), que derivan de la relación de filiación más que de la patria potestad. La referencia a «tenerlos en su compañía» del art. 154 Código Civil español dice relación con la guarda y custodia, que se extiende a las visitas 
respecto del padre no custodio. Además, este deber se puede subsumir en la función de vigilancia y control y colaboración (Cardenal, 2011; Cruz, 2012). Y, finalmente, la función tenerlos en compañía se puede extender de forma excepcional por el juez a terceros encargados del cuidado y atención del menor (art. 103-1 Código Civil español). Sin perjuicio de lo cual, el sistema de custodia unilateral consagrado como general en España, - con las excepciones de las Comunidades Autónomas de Aragón, Valencia, Cataluña, Navarra y País Vasco—, ha sido fuertemente criticado.

En el caso chileno los deberes y facultades del padre no custodio se desprenden claramente de las siguientes normas del Código Civil chileno:

Artículo 224. (...) Éste se basará en el principio de corresponsabilidad, en virtud del cual ambos padres, vivan juntos o separados, participarán en forma activa, equitativa y permanente en la crianza y educación de sus hijos.

Artículo $229.4^{\circ} \mathrm{el} \mathrm{juez} \mathrm{deberá} \mathrm{asegurar} \mathrm{la} \mathrm{mayor} \mathrm{participación} \mathrm{y} \mathrm{corresponsabilidad} \mathrm{de} \mathrm{éstos}$ en la vida del hijo, estableciendo las condiciones que fomenten una relación sana y cercana.

La primera de las referidas disposiciones establece el principio de la corresponsabilidad, que exige una forma de participación activa, equitativa y permanente en la crianza y educación de ambos padres (incluye al padre no custodio). Ello sólo se puede plasmar a través de deberes y facultades conjuntos y propios del padre no custodio a cargo de tribunales, y además exige una concepción de custodia que se construya conforme a los principios del interés superior del niño y corresponsabilidad. No es del caso tratar la doctrina y jurisprudencia chilena, que tímidamente y con bastante oposición han comenzado a desarrollar estos deberes y facultades. A favor Negroni (2013) y Acuña (2016). En contra: Tapia (2013). Pero una forma de lograr esta participación activa, equitativa y permanente en la crianza y educación de sus hijos es la custodia indistinta.

\section{3. ¿Qué sustenta, desde el campo científico, la corresponsabilidad?}

En el campo científico la tendencia predominante es el establecimiento de la corresponsabilidad, que influye en la custodia unilateral, haciendo que el padre no custodio participe en la formación de sus hijos (Suárez, 2010). Incluso, desde vertientes feministas, hay corrientes a favor de la coparentalidad (Scott, 1992).

Antes de la corresponsabilidad, la tendencia era a entender que sólo el padre custodio podía otorgar estabilidad al niño, considerándose al padre no custodio como un elemento disrruptor. Ello justificaba su exclusión a través de una concepción restrictiva de las visitas, que eran supervisadas por el padre custodio. Esta tesis, planteada por Goldstein, Freud y Solnit, se denominó BBI (beyond the best intersts child). El BBI desarrolló el modelo de custodia exclusiva con visitas restringidas para el padre no custodio. Esta tesis, desde los noventa, se encuentra fuertemente cuestionada. Batt (1992) hace un extenso análisis de varios estudios científicos que comparan la custodia exclusiva con relación a la compartida, y que lo llevan a concluir que no sólo es consistentemente mejor ésta que aquella, sino que en algunos casos incluso la custodia compartida con padres separados es mejor que la custodia compartida con padres convivientes (Batt, 1992). A iguales conclusiones llegan varios estudios empíricos (Carlsund, Erikss, Löfstedt, \& Sellström., 2012; Heather, Le Bourdais, \& MarcilGratton, 2005; Maldonado, 2014; Stafford \& Coleman, 2012 y Warshak, 2014), como el influyente Report Bauserman (Bauserman, 2002). En Chile, Donoso y Larraín (2003), y con ciertos reparos Vallejo, Sánchez-Barranco, \& Sánchez-Barranco (2004), llegan a las mismas conclusiones. Sin perjuicio de lo cual, el cuidado compartido presenta problemas en los casos de violencia intrafamiliar, por cuanto algunos padres piensan que la custodia compartida no se puede ver alterada por el juez. Y ello los induce a aceptar la violencia (Fehlberg, Smyth, Maclean, \& Roberts, 2011). Finalmente, también hay estudios comparados que son menos concluyentes, respecto de los beneficios para el niño del tiempo compartido, e incluso de los tiempos que se otorga al padre no custodio (Gilmore, 2006); pero la mayoría de ellos indican que la frecuencia de la relación es significativa, dependiendo de los aspectos emocionales del niño y las habilidades parentales del padre no custodio (Gilmore, 2006). 


\section{4. ¿Cuál es el alcance y contenido de la custodia compartida?}

La corresponsabilidad comprende aspectos respecto de los cuales ambos padres deben ser considerados; y cumple un rol incluso en la custodia compartida. Ello en consideración a que en los casos de custodia indistinta, el padre no custodio no es soberano para tomar decisiones referidas a la potestad, sino que sólo será responsable de su cuidado y de adoptar decisiones relativas a lo cotidiano, durante el periodo de guarda con el hijo (Villagrasa, 2010) o de convivencia habitual (Guilarte, 2009). Si bien el cuidado compartido puede tener una extensión diferente, conforme al interés superior del niño, existe cierto consenso en que en éste debe mantenerse la preferencia por periodos lo más amplios posibles, en atención a la edad y circunstancias personales del niño. Se ha entendido que la alternancia en periodos breves de tiempo resulta perjudicial para el desarrollo de su personalidad. En España, hay sentencias que fijan la alternancia de la guarda de los progenitores en periodos anuales, semestrales, trimestrales, mensuales, quincenales, semanales, e incluso diarios (Sentencia Tribunal Supremo español, 11 de marzo de 2010, por trimestres escolares. Sentencia Audiencia Provincial de Tarragona de 26 de noviembre de 2010 y sentencia Audiencia Provincial Las Palmas, 14 de junio de 2006). De este modo, son mayoritarias las sentencias que van imponiendo un régimen amplio de alternancia, por años o por cursos académicos, al considerarse lo más adecuado para la estabilidad del niño (Villagrasa, 2010). Por consiguiente, la guarda no es conjunta, ni se comparte, sino que configura estancias alternadas, alternativas o sucesivas.

Para Pinto más que un sistema de residencia alternada, el cuidado compartido exige un alto grado de acuerdo de los padres, por cuanto dicha residencia alternada convive con una serie de aspectos propios de la vida del menor que exigen acuerdo, ya sea para ejercicio conjunto o exclusivo. Y ello es consecuencia de una doctrina jurisprudencial (Sentencia Audiencia Provincial de Toledo, $1^{\mathrm{a}}, 2.02 .2005$ y, Sentencias Audiencia Provincial de Barcelona 12a 20.12.2006, 25.07.2007 y 16.10.2007), que ha destacado la diferencia entre un régimen de custodia compartido y uno de custodia repartida por períodos más o menos amplios (Pinto, 2009). Sin embargo, esta posición ha sido dejada de lado, desde que la custodia compartida se presenta como la mejor forma de aplicar el interés superior, aún en caso de conflicto entre los padres. Miranda destaca que la jurisprudencia española ha ido variando desde la exigencia de grados mínimos de conflictividad para conceder la custodia compartida con oposición, a la última jurisprudencia que la desecha sólo en caso que la custodia compartida dañe al niño, como en casos de conflictividad extrema (Miranda, 2010). Picontó (2012), en cambio, señala que desde la Reforma del 2005, los tribunales han comenzado a decretar la custodia compartida con oposición, aunque lentamente.

En la determinación de los tiempos de custodia compartida, en algunos ordenamientos jurídicos, se ha optado por establecer unos presumption of equal time with each parents; aunque, en $R U$ dada la experiencia de Australia y Canadá, se ha desechado esta presunción, agregándose otras, como la adopción de una distribución del tiempo correspondiente a la situación previa a la ruptura (primary caretaker o continuity of care). Esta última presunción es recomendada por el American law Institute (Bix, 2013). En Inglaterra y Gales (mediante the Adoption and Children Bill 2005, 2005-06 HL-96 54/1, subsequently Children and Adoption Act 2006), se ha preferido otorgar a los tribunales y la administración las herramientas para promover el cumplimiento de los tiempos que corresponden al padre no custodio (non-resident parent), e incentivar acuerdos entre los propios padres (Gilmore, 2006). Una herramienta que ayuda a dictar mejores sentencias son los Planes de Parentabilidad, que es el instrumento a través de los cuales los padres pretenden ejercer la responsabilidad parental, estos acuerdos otorgan información para que los jueces puedan decretar los tiempos y formas de custodia más adecuados. Esta figura está regulada en el Derecho español (art. 233-9 Código Civil catalán). Esta propuesta incide en la responsabilidad parental en el cuidado, educación y formación integral del niño, arts. 233-8 y 233-10 Código Civil catalán (Reyes-Barrada, 2014 y Gete-Alonso, \& Calera, 2014). Estas herramientas serían especialmente valiosas dado que la frecuencia de la relación con ambos padres o con el padre no custodio es un presupuesto para el bienestar del niño, 
pero no tienen una relación de causa-efecto (Gilmore, 2006). Por ello para el logro del bienestar del niño, la información que puedan proveer voluntariamente los padres será de vital importancia (Gilmore, 2006). Así, tenemos que el ordenamiento jurídico debe velar por el establecimiento de una instancia formal, que le permita al juez tener información relevante en torno a la forma de custodia, independientemente de la forma que en definitiva fije el juez.

\section{Contenido de la custodia unilateral, exclusiva o indistinta con relación a la patria potestad en el Derecho español y nula aplicación de la corresponsabilidad en el Derecho chileno}

Como destaca Delgado (2010): «[1]a patria potestad, más que un poder de los progenitores, se configura y está orientada como una función establecida en beneficio de los menores, que se reconoce a los padres y que está en función de la protección, educación y formación integral de los hijos, cuyo interés es siempre prevalente en la relación paterno filial». Ello, sin perjuicio de lo cual, el Derecho español exhibe una confusión e indeterminación respecto del contenido de la patria potestad y su relación con la guarda y custodia. Así: «[E]s muy frecuente encontrarse con Profesionales del derecho, Jueces y Fiscales, Psicólogos de equipos psicosociales adscritos a los Juzgados de familia, que piensan que al cónyuge custodio le corresponde tomar la mayor parte de las decisiones relativas a sus hijos, precisamente porque tiene atribuida su guarda y custodia». Esta confusión es fuente de enfrentamientos y solo sirve para intensificar el alejamiento del progenitor no custodio (Delgado, 2010). En igual sentido, Pinto (2009) indica que el concepto de patria potestad se desprende de las sentencias Tribunal Supremo español de 28.10.1891; 25.06.1923; 3.03.1950; 18.02.1969; 9.03.1984; 23.07.1987; 30.10.1996 y 5.03.1998, que la entiende como una función deber/facultad. Así, no cabe duda que la forma de integrar, interpretar y aplicar las normas, que regulan la patria potestad, debe estar inspiradas en el interés superior del niño, integrando el principio de igualdad de los padres.

Ahora bien, específicamente respecto de la custodia exclusiva, la doctrina distingue dos situaciones que se pueden dar: a) que vaya acompañada con ejercicio de patria potestad conjunto o b) con ejercicio de patria potestad total o parcial a favor del padre custodio. Acá se suele distinguir entre guarda o custodia, que comprendería las facultades de educación y crianza relacionadas con lo cotidiano, de ejercicio de la patria potestad que tiene que ver con aspectos más definitivos con relación (Echarte, 2000; Rabadán, 2011; Ragel, 2001; Rivero, 1994). A este respecto se suelen poner ejemplos de titularidad conjunta de la patria potestad, como la elección del colegio, la clase de educación en que se formarán los hijos, el esparcimiento, la elección de religión, la salud, etc. Por ello la doctrina y jurisprudencia española entienden que el contenido de la patria potestad —en su aspecto extrapatrimonial - comprende su educación, formación integral y corrección moderada de los hijos, que se puede contraponer con las funciones de la guarda y custodia, que comprendería velar por ellos y tenerlos en su compañía. Así, para Cruz, el que el cuidado se separe de la patria potestad hace que las facultades de alimentos, y el derecho de educación y formación sean atraídos por el ejercicio de otras funciones. Lo anterior para Cruz se vería avalado por la Reforma del 2005. En consecuencia, el deber-facultad de los padres con relación a los hijos «de velar por ellos» y «de tenerlos en su compañía», a que se refiere el art. 154 del Código Civil español, se vería absorbido en parte por la guarda y custodia. Luego, Cruz extiende la expresión «velar por los hijos», más allá de la propia patria potestad, para ubicarla dentro de una facultad que se desprende de la filiación. En este sentido, Cruz señala que: «[p]or eso el origen de esta función (se refiere a las funciones de «velar por los hijos〉 y 〈tenerlos en su compañía〉) se extiende más allá de la institución de la patria potestad y deriva la relación de filiación, aunque cuando los progenitores ostentan la patria potestad el deber de velar por los hijos queda integrado en esta» (lo destacado entre paréntesis es mío). Y, finalmente, Cruz (2012) indica que estas facultades estarían comprendidas tanto en la guarda y custodia, como en el régimen de visitas, por lo que sería parte de la función de vigilancia y control y de colaboración del padre no custodio. 
Como consecuencia de lo anterior, la asignación de la guarda y custodia a un padre implica que se debe velar por la implementación de los derechos y facultades del otro, por cuanto ellos se desprenden del ejercicio y titularidad de la patria potestad, que sigue siendo conjunta. En este sentido, la custodia unilateral (indistinta) exige un grado de empatía relevante del padre custodio con el no custodio (Guilarte, 2014). El presente trabajo va un poco más allá y señala que el padre no custodio debe estar relacionado con ciertos aspectos de la cotidianidad con respecto del hijo, independientemente de la empatía del otro padre. De este modo se promueve una noción específica de custodia como custodia indistinta, siendo la custodia exclusiva una figura excepcional. Naturalmente que esta concepción de custodia exige relacionar esta figura con la patria potestad.

Existen tres consideraciones conforme a las cuales se puede relacionar y custodia con la patria potestad.

En consideración a la primera, la custodia se refiere a lo cotidiano, pero no tiene relación alguna con su asignación a uno de los padres. De este modo la custodia — entendida como cotidianeidades una verdadera situación de hecho que puede formar parte de la guarda y custodia, como derecho asignado de forma indistinta, o de la comunicación directa y efectiva del padre no custodio. En este sentido, la custodia sería más bien indistinta que exclusiva. Esta es la posición sostenida en el III encuentro de Magistrados y Jueces de Familia y Asociaciones de Abogados de Familia, celebrado en Madrid, los días 28 a 30 de octubre del 2008, que concluye: «... el termino custodia hace referencia a convivencia, no implicando más derechos, y consecuentemente no supone un status privilegiado de su progenitor frente a otro. Se valora positivamente la reforma llevada a cabo por la Ley 15/2005, en el sentido de que en las resoluciones judiciales se han fijado unas estancias más equitativas con los hijos, ampliándose el tiempo de convivencia, que se había estandarizado, con el progenitor no custodio». Esta posición es muy cercana a la custodia compartida, — que exige una residencia compartida o alterna con relación a ambos padres-, y comprendería derechos de filiación relacionados con lo cotidiano (Gómez de la Torre, 2007), y es la posición que se sigue en el presente trabajo. Pero se diferencia terminológicamente con la custodia compartida como ser verá. Una variante de esta posición sostiene que la guarda y custodia hace referencia a aspectos de orden más cotidiano y doméstico y/o de carácter urgente, cuestiones que deben ser resueltas por el padre que la ostenta (Delgado, 2010). La posición imperante que asimila custodia con cotidianeidad en términos relativamente absolutos, —aceptada hace algún tiempo en materia de custodia - debe desecharse. Los principios de corresponsabilidad e interés superior no permiten poder calificar la custodia como exclusiva, por cuanto existen aspectos de lo cotidiano que pueden e incluso deben quedar radicados en el padre no custodio. Por ello es mejor referirse a la custodia como indistinta, es decir, aquella que le corresponde de forma principal al padre que concretamente esté a cargo del niño. En este sentido, se puede señalar que la custodia del padre custodio es principal. Roda y Roda (2014) señala, a este respecto, que: «[E]l modelo de custodia exclusiva será claramente contrario al interés del menor, si el custodio con su actuación perjudica la relación con el progenitor no custodio, obstaculizando el normal desarrollo del régimen de visitas». Pero ello sólo se genera en los casos en que la custodia exclusiva es la regla general. Naturalmente la custodia exclusiva debe aplicarse en caso que el interés superior del niño lo haga necesario, como en los casos de vulneración de derechos por parte del padre no custodio. Así, la custodia exclusiva con régimen de relación directa y regular quedaría reducida a los casos en que el padre no custodio incurra en conductas contrarias al interés superior del niño, que no sean necesariamente objeto de pérdida de los deberes o facultades de filiación, como prostitución, alcoholismo, drogadicción, etc. La custodia exclusiva, dado los principios de la infancia, deber ser necesariamente excepcional. De este modo, en los casos de una relación directa y regular ampliada, el padre no custodio está a cargo de aspectos cotidianos concretos de la relación filial. Esta posición es sostenida por Almeda y Di Nella para los cuales la guarda y custodia, cuando los progenitores no viven juntos, a menudo se asigna en forma exclusiva a uno de ellos.

Una segunda posición sostiene que los conceptos de guarda y custodia son subsumidos en la patria potestad en la medida que los padres vivan juntos; pero en caso que los padres se separen 
se debe agregar el concepto de visitas, que sería parte del ejercicio de la patria potestad. En este contexto para Rabadán habría que referirse a: guarda y custodia; visitas y ejercicio impropio de la patria potestad. Y el contenido de cada uno de estos derechos estaría dado: la guarda y custodia, que implica el ejercicio de facultades concretas de la patria potestad relacionadas con el cuidado directo del niño, que requieren la convivencia, es ostentada exclusivamente por el padre custodio; el derecho de visitas, que corresponde al padre que no vive con el menor, y se plasma en el «tener a los hijos en su compañía»y, finalmente, las facultades de la patria potestad que no están integradas en la guarda serían conjuntas (ejercicio impropio de la patria potestad) (Rabadán, 2011). Esta es la posición tradicional, que conduce a otorgar derechos de filiación desnudos para el padre no custodio, y que señala que la custodia unilateral necesariamente debe ser exclusiva.

Una tercera posición considera que la guarda y custodia, como regla general, nunca puede ser exclusiva; pero agrega que la custodia es la que se relaciona con los aspectos cotidianos del niño, y jamás con el régimen de comunicación del padre no custodio. Y ello se debe a que todo régimen de comunicación y relación personal con el padre, que no convive, en la residencia habitual del niño conlleva que tal exclusividad no exista. Así, habría corresponsabilidad durante el tiempo que el niño se encuentra bajo el cuidado del progenitor no custodio. Esta posición es la más artificial de las tres por cuanto excluye la posibilidad de que el padre no custodio tenga una relación cotidiana con el hijo, y simplemente se presenta como una forma de hacer responsable al padre no custodio de las conductas que generen responsabilidad extracontractual de los padres respecto de sus hijos. La persona responsable de la guarda y custodia, al compartir varias veces a la semana o en el mismo día el cuidado del niño (como la instrucción escolar, actividades de ocio y recreación, etc.), conlleva a que la responsabilidad civil de los padres sea conjunta.

Esta tercera posición no es consistente con entender la guarda y custodia como exclusiva y excluyente, por cuanto supone que es conjunta en torno a la responsabilidad civil de los padres. Esta posición confirma que la custodia debería ser principal — para el padre custodio — y accesoria — para el padre no custodio-, es decir, la custodia debe ser necesariamente indistinta, si se establece la responsabilidad conjunta de los padres. Así, independiente de la residencia más o menos permanente que tenga el hijo con el padre custodio, lo cierto es que no existe ningún sustento que permita justificar la exclusión del padre no custodio de las decisiones relevantes de la vida cotidiana del niño. Ésta posición sólo se justifica en extender la responsabilidad civil al padre no custodio. La responsabilidad civil de los padres excede con creces la presente investigación, pero se vincula con las tres posiciones precedentes a través de la denominada imputabilidad objetiva o culpa objetiva. Este criterio de imputabilidad se puede construir sobre los actos concretos que los padres pueden exigirles a sus hijos respecto de su crianza y educación -en cuyo caso ambos padres podrían ser responsables-; pero en caso que se sigan las posiciones restrictivas respecto de la participación en lo cotidiano del padre no custodio, ello podría jugar como eximente de responsabilidad, a través de la falta de culpa in vigilando. En palabras simple, el padre no custodio, que no tiene incidencia en la crianza y educación del hijo, no puede ser responsable de su delito o cuasidelito civil. Ello supondría saltarse la imputabilidad axiológica que exige el sistema de responsabilidad civil. La relación de estas tres posiciones se evidencia en el Derecho español en el artículo 1903 Código Civil español, que establece que: «[1] os padres son responsables de los daños causados por los hijos, que se encuentren bajo su guarda» (Zarraluqui, 2013).

Antes de entrar a analizar el Derecho chileno. En este ordenamiento jurídico, a pesar de introducirse el principio de la corresponsabilidad —a través de la Ley $\mathrm{N}^{\circ} 20680$ del 2013 — claramente en el artículo 224 Código Civil chileno y reconocerse expresamente el principio del interés superior del niño a través de la Ley $\mathrm{N}^{\circ} 19585$ de 1998, se establece un sistema prácticamente de visitas para el padre no custodio. Así, los derechos del padre no custodio se encausan a través de la relación directa y regular en el artículo $229.1^{\circ}, 2^{\circ}, 4^{\circ}$ y $5^{\circ}$ Código Civil chileno, que establece que:

El padre o madre que no tenga el cuidado personal del hijo tendrá el derecho y el deber de mantener con él una relación directa y regular, la que se ejercerá con la frecuencia y 
libertad acordada directamente con quien lo tiene a su cuidado según las convenciones a que se refiere el inciso primero del artículo $225 \mathrm{o}$, en su defecto, con las que el juez estimare conveniente para el hijo.

Se entiende por relación directa y regular aquella que propende a que el vínculo familiar entre el padre o madre que no ejerce el cuidado personal y su hijo se mantenga a través de un contacto periódico y estable.

Sea que se decrete judicialmente el régimen de relación directa y regular o en la aprobación de acuerdos de los padres en estas materias, el juez deberá asegurar la mayor participación y corresponsabilidad de éstos en la vida del hijo, estableciendo las condiciones que fomenten una relación sana y cercana.

El padre o madre que ejerza el cuidado personal del hijo no obstaculizará el régimen de relación directa y regular que se establezca a favor del otro padre, conforme a lo preceptuado en este artículo.

Sin perjuicio de lo anterior, los tribunales de familia —al igual como lo hacían antes de la promulgación de la Ley $N^{\circ} 20$ 680 - suelen establecer regímenes de relación directa y regular de fin de semana por medio. Otro tanto sucede con los artículos 224 Código Civil chileno, y la regulación de la figura de la autoridad parental (del Título IX del Libro I del CC) — que se entiende que es conjunta - Estas normas son bastantes claras al indicar que los jueces deben establecer facultades y derechos para el padre no custodio. En este sentido es especialmente relevante la norma precedente que establece expresamente que: «Art. 224. Toca de consuno a los padres, o al padre o madre sobreviviente, el cuidado personal de sus hijos. Éste se basará en el principio de corresponsabilidad, en virtud del cual ambos padres, vivan juntos o separados, participarán en forma activa, equitativa y permanente en la crianza y educación de sus hijos».. En igual sentido la doctrina chilena más reciente en esta materia - a pesar que reconoce los principios de la corresponsabilidad e interés superiorarticula simplemente un sistema de facultades y derechos desnudos para el padre no custodio (Acuña, 2018 y Rodríguez-Pinto, 2018). En torno a la relación entre custodia — que en Chile se denomina cuidado personal - y responsabilidad de los padres, Acuña agrega que, en Chile, la responsabilidad de los padres por los hechos del hijo, ya sea como guardián (art. 2.319.1 ${ }^{\circ}$ Código Civil chileno) o como vigilante (art. 2.320.2 ${ }^{\circ}$ Código Civil chileno) o por el hecho propio de ellos (art. 2321 Código Civil chileno) debe reinterpretarse conforme al artículo $18.1^{\circ} C D N$ (Acuña, 2012). Dicha norma establece que: «[1]os Estados Partes pondrán el máximo empeño en garantizar el reconocimiento del principio de que ambos padres tienen obligaciones comunes en lo que respecta a la crianza y el desarrollo del niño. Incumbirá a los padres o, en su caso, a los representantes legales la responsabilidad primordial de la crianza y el desarrollo del niño. Su preocupación fundamental será el interés superior del niño». Esta diferencia es muy importante por cuanto la distinción entre deberes y facultades del padre no custodio, —en la medida que se concreticen-, deben llevar aparejada consecuencias por los actos del niño, aunque éste no esté bajo el cuidado temporal del padre no custodio. De este modo, si el padre no custodio participa en la crianza y educación cotidiana de su hijo, le cabe responsabilidad civil por los hechos ilícitos que éste cometa con capacidad. En el caso de incapacidad, en materia de responsabilidad extracontractual, sólo responderá como guardián, es decir, si le es exigible un deber de cuidado en concreto.

Lo que el presente trabajo recalca, es que la posición que disocia entre la guarda y custodia y patria potestad, aunque fue un avance, por cuanto establece decisiones conjuntas de los padres (las relevantes), y evita en parte un sistema de derechos de filiación desnudos para el padre no custodio, al determinar una custodia exclusiva, conduce a un alejamiento del padre no custodio respecto de su hijo. Delgado (2010) señala que el régimen dual de patria potestad, por una parte, y guarda y custodia por la otra — más allá de la excepcionalidad de la guarda compartida — propicia que el padre no custodio, vaya perdiendo, aunque sea de un modo inconsciente, la percepción de la propia responsabilidad respecto de sus hijos. Esta es la posición que asigna el contenido de la patria potestad al padre custodio, con relación a los aspectos cotidianos o diarios, es la que ha predominado en España 
y ha sido fuertemente criticada. A esta tesis se adscribe Guilarte (2014) cuando señala que: «[E]n este sentido, el progenitor que tenga atribuida la guarda será quien decida en la esfera diaria y ordinaria del menor, requiriendo la presencia del otro progenitor para concluir los actos que excedan de aquella, como por ejemplo, la necesidad o conveniencia de una intervención quirúrgica, colegio en el que va a estudiar, educación religiosa que va a recibir, viajes de larga duración, cambio de domicilio o de país de residencia». Esta tesis ha llevado a Delgado (2010) a señalar que las soluciones legales en vigor favorecen, al menos indirectamente, una situación de marginación con el consiguiente abandono y dejación de funciones del padre no custodio. Y ello supone «orientar la relación familiar hacia lo patológico». Por ello es precisamente que parte de la doctrina española aboga por la supresión del término guarda y custodia, pues la eliminación de ese «estigma formal» y de ese elemento diferenciador y discriminador, potenciará acuerdos entre los progenitores. Suprimido el concepto de custodia, la discusión se centrará exclusivamente en el reparto entre los padres del tiempo que han de permanecer los hijos con cada uno (Zarraluqui, 2003). Pinto (2009) plantea una posición semejante al señalar «un régimen de visitas reparte los tiempos de convivencia; la custodia compartida también, pero reparte además la implicación y la responsabilidad que se dimanan del ejercicio diario y cotidiano de la patria potestad, lo que no acontece en el régimen de visitas, por muy amplio que sea». La posición precedente justifica el que muchos países hayan optado por sistemas privilegiados, legales y supletorios de cuidado compartido. Incluso, en el Derecho español, el establecimiento de amplios regímenes de derechos y facultades para el padre no custodio ha llevado a sostener que el Derecho genera una verdadera custodia compartida. Existe una nutrida jurisprudencial, antes de la Reforma del 2005 y que se mantiene en la actualidad, en este sentido y que califica como custodia compartida una custodia unilateral con un amplio régimen de visitas (SSAAPP, Oviedo, 5a , 26.09.2006, Zaragoza, $\left.2^{a}, 5.06 .2007\right)$. En contra de esta tendencia generalizada están: Pinto (2009) y Campuzano (2005). Frente a estas discusiones lo que se propone es una reformulación de la custodia, a través del concepto de custodia indistinta.

En la mayoría de las legislaciones se utiliza la expresión de guarda o custodia y cuidado exclusivo para referirse al cuidado unilateral. En estos ordenamientos jurídicos se transgrede la $C D N$ al opta por mantener los aspectos cotidianos de la crianza y educación en favor del denominado padre custodio. La guarda y custodia exclusiva atribuye al progenitor, que convive con el hijo, cuestiones relativas a su cuidado y educación, derivadas de la convivencia y el contacto diario con el hijo. Esta posición, que era sostenida por la mayoría de la doctrina española y que aún es sostenida en la chilena, debe corregirse. El sistema que establecía que lo cotidiano correspondía exclusivamente al padre que tenía la guarda o custodia, - o el cuidado personal, en el Derecho chileno - debe revisarse. Es verdad que dicho sistema también establecía que las cuestiones sobre la crianza, cuidado o la educación de los hijos, que no precisan del contacto diario, exceden del ámbito de la guarda y custodia y pertenecen al ámbito de la patria potestad (en el Derecho español) o la autoridad parental o corresponsabilidad en el Derecho chileno. Y en este sentido se aplicaba, aunque tímidamente, los principios de la corresponsabilidad e interés superior del niño, no es suficiente. Pero aún esta distinción, que reconoce que hay ciertos aspectos conjuntos - es decir que excluye algunas facultades y derechos del cuidado exclusivo - no se reconoce en Chile. En Chile, esta importante distinción no es pacífica. Esto se debe a que, en Chile a diferencia de otros países, de la jurisprudencia de tribunales se desprende claramente que no existe una dimensión conjunta de deberes y facultades de filiación. Este problema se resuelve en el Derecho español estableciendo una patria potestad compartida por ambos padres, tanto respecto de su titularidad como ejercicio, aún en los casos de guarda y custodia unilateral. Sin embargo, en el caso chileno este problema tiene una clara solución normativa. En consideración a ella es posible delimitar qué asuntos son competencia del guardador y cuáles han de decidir ambos progenitores, como se desprende del principio de corresponsabilidad establecido en el artículo 224 Código Civil chileno; la regulación de la relación directa y regular del artículo 229 Código Civil chileno; o la regulación de la autoridad parental. Por ello, hay decisiones, de índole educativo, religioso o sanitario, que no forman parte de la guarda y custodia, porque además no requieren de convivencia. Así: «la 
elección del colegio en el que cursará sus estudios el niño, la educación religiosa que va a recibir, los viajes de larga duración que va a realizar, el sometimiento a una concreta intervención quirúrgica, el pronunciamiento por un determinado tratamiento médico o por la práctica de una concreta actividad educativa» (Rabadán, 2011). Así, en Chile, lamentablemente, estos aspectos todavía no se analizan por parte de nuestra dogmática, a pesar de tener sustento normativo en los artículos 224 y 229 Código Civil chileno.

\section{Las distintas tipologías de custodia que se proponen en caso que los padres no convivan}

a) Custodia exclusiva. Esta es la forma en que tradicionalmente se ha entendido la guarda y custodia. Así lo cotidiano se hace sinónimo de custodia, y como ella se le concede al padre custodio, la cotidianidad queda excluida respecto del padre no custodio. En el presente trabajo la custodia exclusiva se plantea como excepcional y opera en casos graves para proteger a los niños.

b) Custodia indistinta. En ella la mayoría de los aspectos cotidianos corresponden al padre custodio, pero el padre no custodio está a cargo de ciertos aspectos cotidianos. En esta clase de custodia, que se plantea como la general, un padre tiene un tiempo de residencia con su hijo mucho mayor que el otro, por tanto no cabe confundirla con la custodia conjunta o alternada. Esta custodia sería la regla general, pero ello no impide que el juez recurra a la custodia exclusiva en caso que el padre no custodio este imposibilitado legalmente de hacerse cargo de los aspectos relativos a la cotidianidad del niño.

c) Custodia conjunta o alternativa. En ella habría un ejercicio completo y simultáneamente ejecutado por ambos progenitores. Para una parte minoritaria de la doctrina la custodia conjunta sólo puede desarrollarse en el marco de una convivencia de los padres con el niño (Almeda \& Di Nella, 2010). Esta terminología se ocupa mayoritariamente para referirse a los casos de padres separados que compartan la custodia, ya sea de forma alternada o sucesiva, e incluso conjunta. En estos casos se exige que la convivencia con ambos padres sea relevante en porcentajes de a lo menos 70/30 (Nikolina, 2015).

Para Almeda y Di Nella la custodia compartida puede ser simétricamente o asimétrica. En el primer caso, los padres, conviviendo o no, comparten paritaria y alternativamente todas las gestiones del bienestar de los niño en partes iguales (50/50). Así, cuando no hay convivencia se constituyen dos familias monoparentales a tiempo parcial y sucesivo. Para algunos autores la custodia compartida asimétricamente exige una guarda principal y otro/a secundaria, o de responsabilización aleatoria o circunstancial. En el presente trabajo se estima que en caso de darse, por una parte, una guarda principal o residencia habitual con el niño y, por la otra, un régimen de comunicación y relación personal de alternancia temporal — más de un fin de semana por medio- en que existan funciones u obligaciones puntuales - llevarlos al colegio, compartir el ocio, asistirlos en su salud o en los estudios, entre otras - respecto al otro padre, se trata en realidad de una custodia indistinta. Sin embargo, Almeda y Di Nella entienden esta última situación como un caso de custodia compartida asimétrica (Almeda \& Di Nella, 2010). El tema no es menor por cuanto nuevamente el entender la custodia indistinta, como compartida, es una forma de debilitar una aplicación adecuada del principio de corresponsabilidad. Ello se debe a que la custodia compartida es la situación ideal (es la situación en que se aplica la corresponsabilidad y el interés superior en su sentido máximo); en cambio la custodia indistinta — aunque compatible con los principios de corresponsabilidad e interés superiorlogra un menor desarrollo de los derechos de la personalidad del menor. Esta posición, que hace sinónimos ambas figuras, se establece en el nuevo Código Civil y Comercial argentino. Así, Cataldi (2015) sostiene, respecto de la Reforma Argentina 2014, que:

el art. 650 establece las distintas modalidades del cuidado personal compartido: Alternado: el hijo pasa periodos de tiempo con cada uno de los progenitores, según la organización y posibilidades de la familia. Indistinto: el hijo reside de manera principal en el domicilio de 


\section{LA CUSTODIA INDISTINTA, COMO CONCEPTO PRIVILEGIANDO, FRENTE A LA CUSTODIA EXCLUSIVA \\ COMO FORMA DE CUSTODIA UNILATERAL}

uno de los progenitores, pero ambos comparten las decisiones y se distribuyen de modo equitativo las labores atinentes a su cuidado, con independencia del lugar donde el niño reside. (p. 5)

En igual sentido, Herrera y Lathrop (2017) sostienen que la legislación argentina tiene una preferencia por la custodia indistinta, más que por la alternada.

\section{Resultados y conclusiones: la aplicación mínima de los principios de corresponsabilidad e interés superioridad del niño exigen que la custodia indistinta sea la regla general y la exclusiva la excepción}

a) El presente trabajo hace una aplicación de los principios de la corresponsabilidad parental e interés superior, que llevan a que uno de los padres no puede ser excluido de la crianza y educación de los hijos, sino en casos graves (sólo en ellos se justifica la custodia exclusiva).

b) Los referidos principios nos permiten distinguir tres formas de custodia: compartida, indistinta y exclusiva. Las dos primeras formas de custodia se pueden aplicar como regla general, en cambio la custodia exclusiva es necesariamente excepcional. Ello por cuanto los principios de interés superior y de corresponsabilidad llevan a que tal exclusividad no exista. Así, a lo menos, en los ordenamientos jurídicos que establecen los principios del interés superior y corresponsabilidad, aunque la guarda para el padre no custodio esté disminuida o durante el tiempo en que se encuentre bajo el cuidado del padre no custodio, ésta debe participar en aspectos concretos de la cotidianeidad del niño. Es más, en sentido amplio, el padre custodio debe compartir el cuidado del niño varias veces a la semana o en el mismo día (como si el padre no custodio participa en la instrucción escolar; en actividades de ocio y recreación; realiza un cuidado específico en casa del padre custodio; participa en actividades de familiares, amigos, vecinos; lleva al hijo a clases privadas, etc.). Por ello la guarda y custodia, más que exclusiva, es principal. Las consecuencias de concebir la guarda y custodia como exclusiva y excluyente no sólo afecta a la corresponsabilidad parental respecto del padre no custodio, sino que es el no reconocimiento jurídico del grupo de convivencia familiar monoparental del padre no custodio (Almeda \& Di Nella, 2010), y naturalmente atenta contra el principio del interés superior.

c) Este trabajo permite distinguir entre custodia compartida e indistinta, como regímenes generales de custodia. La custodia compartida exige tiempos de residencia altos, siendo el mínimo de un 30\% para un padre, y también un grado importante de participación en la cotidianeidad del niño respecto de ambos padres en grados de igualdad. El régimen de custodia indistinto exige que haya un padre custodio (que mantiene la residencia principal), pero el padre no custodio tiene necesariamente que hacerse cargo de aspectos específicos del cuidado cotidiano del niño. En cambio, en un cuidado exclusivo el padre no custodio está inhabilitado de participar en los aspectos cotidianos de su hijo. En la custodia indistinta es verdad que el padre custodio será el encargado de la mayoría de los aspectos cotidianos del niño; pero el padre no custodio igualmente participa de estos aspectos. Por ello es un grado menor de corresponsabilidad con relación a la custodia compartida.

d) Como, en el sistema de cuidado indistinto, el padre no custodio participa en la cotidianeidad de la vida del hijo, el juez debe contar con los medios de prueba que le permitan determinar los aspectos cotidianos respecto de los cuales el referido padre pudiese hacerse cargo. Así, ello se puede lograr a través de los Planes de Parentalidad, o escuchando al padre no custodio y al propio hijo.

e) La custodia compartida es el régimen más adecuado para la infancia, conforme a los estudios a los que se ha hecho referencia, pero la custodia indistinta no viola los principios basales del Derecho de infancia, ni tampoco la custodia exclusiva en la medida que sea un régimen especial y excepcional.

\section{Lista de referencias}

Acuña, M. (2012). ¿Quién responde por los daños causados por un menor de edad cuando sus padres viven separados. El Mercurio Legal. Recuperado de: http:/www.elmercurio.com/Legal/Noticias/ 
Analisis-Juridico/2012/05/11/Quien-responde-por-los-danos-causados-por-un-menor-de-edadcuando-sus-padres-viven-separados.aspx

Acuña, M. (2016). Relaciones jurídicas entre los padres y el (la) hijo (a). Filiación. En Del Picó (Dir.), Derecho de Familia (pp. 423-538). Santiago de Chile: Thomson Reuters.

Acuña, M. (2018). El cuidado personal de los hijos. Colección Tratados y Manuales. Santiago de Chile: Thomson Reuters.

Almeda, E., \& Di Nella, D. (2010). Monoparentalidad y responsabilidad parental. En T. Picontó (Ed.), Custodia Compartida (pp. 101-130). Madrid: Dykinson.

Barcia-Lehmann, R. (2017). Hacia una mirada integral del Derecho de la Infancia: deberes y facultades del padre no custodio en el Derecho chileno. Revista de Derecho Privado, 32, 219254. ooi:10.18601/01234366.n32.08

Batt, J. (1992). Child custody disputes and the beyond the bes interests paradigm: A contemporary assessment of the Goldstein/Freud/Solnit Position and the Group's Painter v. Bannister Jurisprudence. Nova Law Review, 16, 621-685.

Bauserman, R. (2002). Child adjustment in joint-custody versus sole-custody arrangements: A metaanalytic review. Journal of Family Psychology, 16(1), 91-102. doi:10.1037//0893-3200.16.1.91

Bix, B. (2013). Family Law. New York: Oxford University Press.

Campuzano, T. (2005). La custodia compartida: doctrina jurisprudencial de las Audiencias Provinciales. Revista Aranzadi Civil, 22, 15-48.

Cardenal, R. (2011). Patria potestad. En F. Lledó, \& A. Sánchez (Eds.) Derecho de Familia, (pp. 435483). Madrid: Dykinson.

Carlsund, A., Eriksson, U., Löfstedt, P., \& Sellström, E. (2012). Risk behaviour in swedish adolescents: Is shared physical custody after divorce a risk or a protective factor? European Journal of Public Health, 23(1), 3-8. doi:10.1093/eurpub/cks011

Cataldi, M. (2015). La noción de coparentalidad y el derecho de los hijos a vivir en familia. Recuperado de: http://www.nuevocodigocivil.com/wp-content/uploads/2015/06/La-noci\%C3\%B3n-decoparentalidad-y-el-derecho-de-los-hijos-a-vivir-en-familia-por-Myriam-M.-Cataldi.pdf

Cruz, B. (2012). La guarda y custodia de los hijos en las crisis matrimoniales. Madrid: La Ley.

Delgado, G. (2010). La custodia de los hijos. La guarda compartida: opción preferente. Madrid: Thomson Reuters.

Donoso, A., \& Larraín, S. (2003). Algunas consideraciones sobre el sistema de custodia compartida. De Familias y Terapias, 27, 61-72.

Echarte, A. (2000). Patria potestad en situaciones de crisis matrimonial. Granada: Comares.

Fehlberg, B., Smyth, B., Maclean, M., \& Roberts, C. (2011). Legislating for shared time parenting after separation: A research review. International Journal of Law, Policy and the Family, 25(3), 318-337. doi:10.1093/lawfam/ebr015

Gete-Alonso, M., \& Calera, J. (2014). Filiación y potestad parental. Valencia: Tirant lo Blanche.

Gilmore, S. (2006). Contact/shared residence and child well-being: Research evidence and its implications for legal decision-making. International Journal of Law, Policy and the Family, 20(3), 344-365. doi:10.1093/lawfam/eb1016

Gómez de la Torre, M. (2007). El sistema filiativo chileno: filiación biológica, por técnicas de reproducción asistida y por adopción. Santiago de Chile: Jurídica.

Guilarte, C. (2009). El ejercicio de la patria potestad en situaciones de ruptura convencional. En C. Guilarte (Coord.), Aspectos civiles y penales de las crisis matrimoniales (pp. 75-100). Madrid: Lex Nova.

Guilarte, C. (2014). La concreción del interés del menor en la jurisprudencia del tribunal supremo. Valencia: Tirant lo Blanch.

Heather, J., Le Bourdais, C., \& Marcil-Gratton, N. (2005). Sharing roles, sharing custody? Couples'. Journal of Marriage and Family, 67, 157-172. doi:10.1111/j.0022-2445.2005.00012.x 


\section{LA CUSTODIA INDISTINTA, COMO CONCEPTO PRIVILEGIANDO, FRENTE A LA CUSTODIA EXCLUSIVA COMO FORMA DE CUSTODIA UNILATERAL}

Herrera, M., \& Lathrop, F. (2017). Relaciones jurídicas entre progenitores e hijos desde la perspectiva legislativa latinoamericana. Revista de Derecho Privado, 32, 143-173. doi:10.18601/01234366. $\mathrm{n} 32.06$

Maldonado, S. (2014). Shared parenting and never married families. Family Court Review, 52(4), 632-638. doi:10.1111/fcre. 12113

Miller, M. (2006). Through the eyes of a father: How PRWORA affects non-resident fathers and their children. International Journal of Law, Policy and the Family, 20, 55-73. Recuperado de: https:// ssrn.com/abstract $=915441$

Miranda, M. (2010). La protección de menores: una perspectiva constitucional. Madrid: Consejo General del Poder Judicial.

Negroni, G. (2013). Corresponsabilidad parental: un cambio de enfoque radical. Revista Chilena de Derecho Privado, 21, 103-126.

Nikolina, N. (2015). Divided parents, shared children. Londres: Intersentia.

Picontó, T. (2012). The equality rights of parents and the protection of the best interests of the child after partnership breakdown in Spain. International Journal of Law, Policy and the Family, 26(3), 378-400. doi:10.1093/lawfam/ebs010

Pinto, C. (2009). La custodia compartida. Barcelona: Bosch, S. A.

Rabadán, F. (2011). Ejercicio de la patria potestad cuando los padres no conviven. Madrid: Aranzadi Thomson Reuters.

Ragel, L. (2001). La guarda y custodia de los hijos. Derecho Privado y Constitución, 15, 297-298.

Reyes-Barrada, O. (2014). La planificación judicial de las relacione paterno-filiales en Cataluña. Relaciones Paterno-Filiales, 2, 143-156.

Rivero, F. (1994). Matrimonio y divorcio. En J. Lacruz (Coord.), Comentarios al Título IV del Libro Primero del Código Civil. Madrid: Civitas.

Roda y Roda, D. (2014). El Interés del menor en el ejercicio de la patria potestad. Pamplona: Thomson Reuters-Aranzadi.

Rodríguez-Pinto, M. S. (2018). Manual de Derecho de Familia. Santiago Chile: Editorial Jurídica.

Scott, E. (1992). Pluralism, parental preference, and child custody. California Law Review, 80(3), 615-672. doi:10.15779/Z380Q7W

Stafford, M., \& Coleman, M. (2012). The good, the bad, and the ugly: Divorced mothers' experiences with coparenting. Family Relations, 61(4), 586-600. doi:10.1111/j.1741-3729.2012.00718.x

Suárez, L. (2010). Casa do pai, casa da mãe: a coparentalidade após o divórcio. Psicologia: teoria e pesquisa, 26(1), 77-87. doi:10.1590/S0102-37722010000100010

Tapia, M. (2013). Actualidad Legislativa. Comentarios a la reforma del cuidado personal de los hijos (ley No 20 680). Revista Chilena de Derecho Privado, 21, 477-491.

Vallejo, R., Sánchez-Barranco, F., \& Sánchez-Barranco, P. (2004). Separación o divorcio: trastornos psicológicos en los padres y los hijos. Revista de la Asociación Española de Neuropsiquiatría, 92, 91-110.

Villagrasa, C. (2010). La custodia compartida en España y en Cataluña: entre deseos y realidades. En T. Picontó (Ed.), Custodia Compartida. Cuadernos de Derecho Judicial Bartolomé de las Casas (pp. 76-99). Madrid: Dykinson.

Warshak, A. (2014). Social science and parenting plans for young children: A consensus report. Psychology, Public Policy and Law, 20(1), 46-67. doi:10.1037/law0000005

Zarraluqui, L. (2003). El menor en las crisis familiares. Jornadas sobre Derecho de los Menores, Universidad Pontifica Comillas, Madrid, España.

Zarraluqui, L. (2013). Marco jurídico paterno-filial en las rupturas de pareja. Barcelona: Bosch. 